\title{
HIGHER TECHNICAL EDUCATION - RESEARCH VS. EDUCATION. TECHNIQUE OF TEACHING, BETWEEN CLASSICAL AND MODERN
}

\author{
PÂMîNTAŞ Eugen \\ Mechanical Faculty /Materials and Manufacturing Engineering, Politehnica University, Timisoara, Romania, \\ eugen.pamintas@upt.ro
}

\begin{abstract}
The results, not at all encouraging the graduates and the growing gap between the requirements of the employers and the graduate knowledge base bring us some questions and the look for the most appropriate answers. Of them, the work stops at two, namely: higher technical education prepares engineers, research scientists, or both, respectively, the teaching methods in engineering education today are appropriate? In search of answers and solving problems arising from questions shall be made an analysis of the educational process and master's degree. The analysis is based both on documents and facts generally known, but also the authors' own teaching experience. Conclusions are warning signals for improving the training of engineers and master of technical education but also to reform education in proper selection and training support staff for research.
\end{abstract}

Key words: selection of graduates, researcher, engineer, teaching techniques

\section{Introduction}

The role of education in a society is defined as a provider of education and knowledge. In all its components, learning is characterized by a strong conservative tint regarding didactic principles, organization, knowledge transmission, periodic assessment and their final certification. But training content is regularly updated, including both new knowledge in areas such as science and trends imposed by economic and social needs towards continuous development of human society.

From the brief presented clearly result the role of initiator, continue and further develop in human knowledge that it is education. What society needs individuals alike who know "to do" but also those who "imagine" what and how to do, learning to be leveled on the two major components. This is "resolved" in a first step by organizing education of "general culture" - which cycles corresponding primary and secondary education - and respectively "higher education" - which includes the bachelor, master, doctoral and postdoctoral - first cycle in the category of instruction "how to do well", the second is part of training "how to do it better" and the last two are part of training in "how could make it more well or in some other way."

Since treatment of the subject from the beginning has been made in terms of knowledge in order to "make", is time to insert the new criterion of "splitting" in terms of higher education, namely, to individualize technical higher education as the dealing with the provision of the type of knowledge which aims "the conception and execution of goods, regardless of their physical nature".

Classification sui generis previously done is to provide another perspective on edu - process, on the one hand, and on the other hand, to serve as initial support in addressing future responses to issues raised by the subject of this paper:

- Technical higher education is the preponderance for Engineering or for Scientific Research?

- How would it be better to provide information in the technical education in universities, in the classic manner or using the latest technology tools developed by IT?

Without claiming an exhaustive treatment of the two issues, this paper will study several aspects in order to provide some answers and possible solutions for implementing them, and not least, perhaps the very approach to this important issue in higher technical education portfolio will arouses interest and lead to further debate and research in academic Romanian environment, essentially generating new approaches to improve the educational system and made it compatible with the requirements of current social needs and particularly from predictable horizon of labour market needs. 


\section{Teaching and Research Components in Universities \\ Teaching Component}

Let's rise a critical look on all technical issues of higher education in the last 20 years seen in the light of generic indicators: number of graduates, the number of employed in their field of study, the results obtained by students in technical education during the years of studies, etc., both the author's own experience - undocumented than as personal opinion, as well by analysis and forecast studies conducted by governmental or private organizations specialized - documented via approved articles and publications [1], a generally valid conclusion emerges: all indicators listed above marked a decline objectively characterized by the word "drastically" or a subjective expression, "dramatically".

The mentioned studies have searched the causes of the decline notified and can be classified as social, demographic, legislative, budgetary allocations, etc. therefore outside educational process, but also its internal: wrong decisions, organizational deficiencies, unfounded financing, changes in weight of components training methodologies etc.

Of interest to those who conceive curricula and teaching staff responsible for preparing analytical programs of disciplines is more detailed research of changes in the structure of the components activities of engineering disciplines. With reference to this subject can show that the changes occurred in the last 15 years has been in favor of teaching hours and at the expense of practical instruction, especially of the design activities, both at the level of undergraduate studies (Fig. 1), as especially those of master (Fig. 2).

The authors believe that the notified issues have had and will have negative repercussions on the
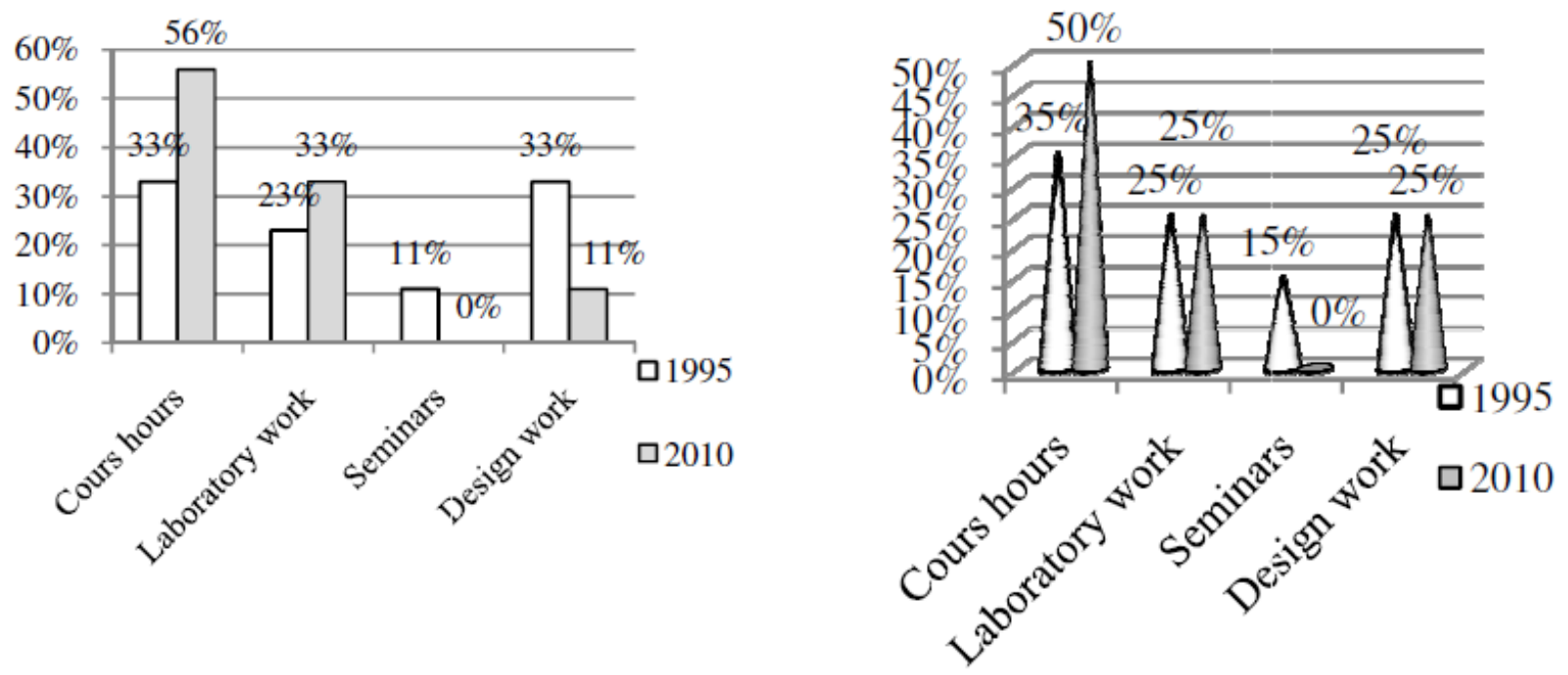

Fig. 1. Bachelor's Degree Components Evolution

Fig. 2. Master Degree

Components Evolution

knowledge acquired by the students and the skills they acquired in the sense that the gap between theoretical and practical knowledge of graduate education engineers make it less and less eligible for operators of labor market, which commonly require general technical knowledge but practical experience, individual technical skills, habits of teamwork in multi-language and cultural groups.

Skills required by employers in the areas listed may fulfill especially in project activities, laboratory and productive practice, i.e., exactly on behalf of components that have recorded the strongest decline. Is unthinkable an inability licensed engineer in product design or technology, how in fact all is unthinkable and for a master's degree in engineering that do not possess the $\mathrm{ABC}$ of the research activity.

\section{Research Component}

The research component of higher technical education is special reference to education as a master's engineers should receive the basic training regarding of the research activity assumes content. Fundamental research is to investigate the basic phenomena, whose power is necessary to deepen knowledge about the nature. Its task is to provide the knowledge required by the need to transform nature in support of civilized humankind. In this way master graduates could handle a research assistant positions or continuing education the cycle of doctoral studies.

Training in technical research in higher education is almost completely unregulated in terms of curricular areas and curricula. There are some exceptions, in that some specializations include one, two courses 
explicitly dedicated to the research issues (e.g. the discipline "Basics of experimental research in mechanical engineering").

Therefore, almost exclusively the training in research is left to the professor, through course content and the application hours. Moreover, teachers have not any special training attested in research work (although this is no exception, but generally, included as the work task in the job description), except who under the guidance of a $\mathrm{PhD}$ leader or self learned during the development of their doctoral studies or who by virtue of the institutional attestations based on criteria were authorized as leadership on $\mathrm{PhD}$ activity (Usualy this task was entrusted to the best and most experienced teachers, today covering positions by other criteria, or even in their absence, and training is the so-called modern technology to "break the link between teacher and student and favors absenteeism or sleeping in the projection rooms better than in an well-lit amphitheater "[2]). Their requirements to the students, their education system are not usually oriented towards highlighting young talented and with creative power.

Experience shows that a regular teacher is not necessarily equipped with the skills of the evaluator and teacher of creative characteristics of students. Moreover, and worse for educating young people for science based subjects are not taught at the appropriate level.

Neither the selection situation of engineers to be trained, in research work does not show better. Selection is entirely at the discretion of a commission that between the interested persons, who are legally eligible, analyzes and evaluates specific criteria and indicators also conceived itself of which essential is the average obtained in graduation degree. The quality of the selection so made can be seen both in the light of low number of doctoral candidates, of substantially "dropout" during these trials and the very small number of industrial implementable outcomes (innovative products, patents, new technologies, etc.) obtained in following the completion of doctoral studies. That is why the selection of graduates in employment after the exams notes is very risky. This was felt by big companies who transferred this task to a service or a recruiting firm specializing in through evaluation and job placements.

Completion master and especially of those doctoral research allows filling positions provided for in the Catalog of Occupations in Romania (COR). These occupations were recorded and accredited based on a set of competencies declared as being obtained by master and for doctoral studies but very difficult to prove through names of courses and especially their contents revealed by the analytical programs of these disciplines provided for in educational plans.

In these circumstances, it is not surprising that although researchers are fewer positions available for contest at research institutes; the competition to fill them is almost nonexistent. On the other hand Higher Education Institutes have only of very small measure of teachers who have at the same time Researchers in the true sense of the quantum to be lived for and research work done by all the rules of this job. Therefore, the performance of Romanian research many as they are, are the result of researchers trained in the end of previous millennium and for the beginning of the current and sometimes of the outstanding talent of young researchers and less of a concerted effort by government or academic factors. A brief look at previous short presentation proves that there are some internal problems, which should be considered seriously and solved wisely and sustainably. All are of interest, but in this paper we address only the sequence of transmission of knowledge and information. This is because we consider it as an essential activity - due to the number of hours specified in the curriculum for each field of study (typically occupies $30-55 \%$ of total) - and an crucial activity - given that it is the first activity that student comes in contact every field of study, it set the tone and all other activities gravitates around it and its applications.

\section{Technique of Teaching in Universities, Between Classical and Modern Transmission and Reception of Knowledge}

The transmission of knowledge in Romanian universities is during the hours allocated through the curriculum, mainly in teaching activities (lectures). Knowledge taught aimed a gradual established by covering chapters from the "Syllabus". At the university level there is no a so-called formal "lesson plan" so that discipline holder is free to choose between the means and techniques of teaching, so that on the one hand to provide the knowledge needed, and on the furthermore, to ensure the attractiveness and interest to students.

Among the teaching methods, the most used are: dictation, academic lecture, demonstration, debate and presentation with IT support. Of these, only the last method can be called modern, the other being part of classical heritage education.

Teaching experience shows that teacher rarely approaches these five styles according to the subject which must be exposed. Most often we have the teachers which address mainly one of them. As such, we have teachers "dictators", "speakers" "demonstrators", "mediators and "presenters". 
What types of students are formed through the five teaching styles? Teaching experience reveals we have students from the following categories: "scribes", "listeners", "followers", "active" and "viewers". In fact the last category can easily transit through the "sleepy" and the first to "copyists dreamers" (see Fig. 3). If the style of "oratorical" is correct in practice as the approach and scope, i.e.: rhetoric, acting, gesticulation, facial expression, debate, dialogue, emphasis in written and special warnings then lecture is easily perceived and understood and the student is responsive and away from boredom. If, in addition, is added IT examples techniques in short, specific with possibly animated at the level of function performed the transmission of knowledge is superior efficient.

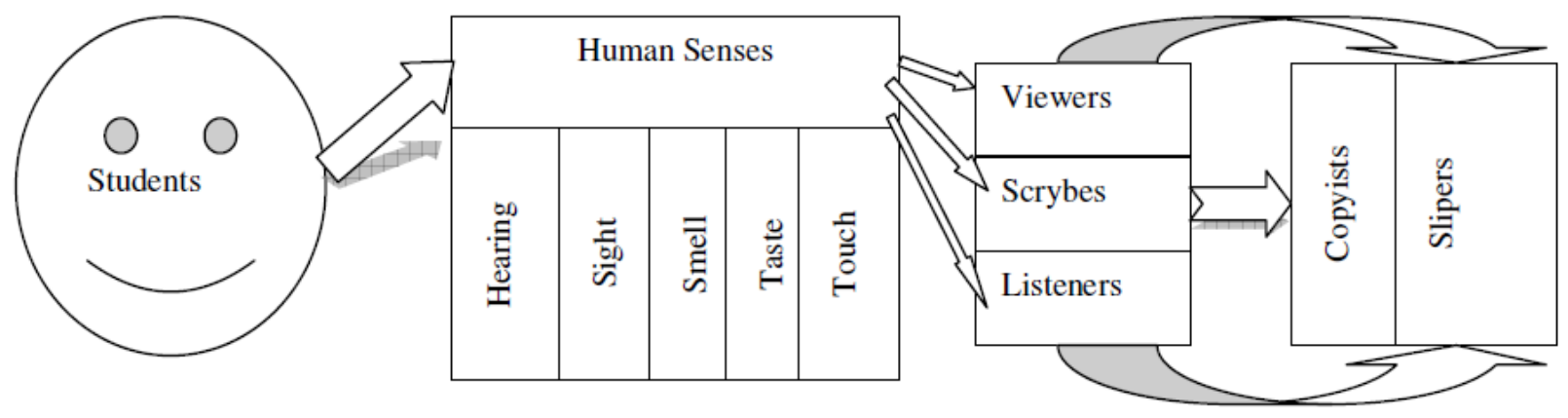

Fig. 3. How the senses participate in the transformation of audience behavior in a course

The presented is a description of a state of facts. So we took note of something that exists. A first idea resulting from this is that teaching style is one that sets the tone for educational activity. It imposes putting a question at least though: why consider that academic lecture with selective IT support style is more appropriate to knowledge transmission? To answer we must consider the phenomenon of sending and receiving of information, i.e. the means of transmission and reception channels.

\section{With Regard to Transmission and Reception of Information Channels}

Human anatomy and physiology reveals that man comes into contact with the outside world through his senses. Any kind of knowledge is made by man through his senses first and then rational thinking deductive and inductive. The general topic of the paper we make a review of the senses and we shall analyze in terms of way in which they participate during training activities, especially at the reception of knowledge handed over in class.

Sense of smell - is the genetically oldest human sense. Nietzsche linking olfactory sense by instinct, by intuitive knowledge and in this way smell provided the sensory model for a practical pre-conceptual knowledge [3]. That is why your nose is assigned as metaphorical significance: clairvoyance, insight, in short "practical intelligence" or as Dgastra Rolf says is a "measure of feeling spirit and intellect" [1]. This sense is, however, less important for teaching but should not be full underestimated. You cannot perform scientific lecture on restaurant or fish warehouse, but we are interested in or hinders us the smell in amphitheater or of bank colleague or even of the teacher.

Sense of taste - a sense of contact through which only when transmitting practical know, it receives a characteristic of the subject: sweet, sour, bitter, salty or combinations thereof and as such its importance for the purposes of our analysis is negligible.

Sense of touch - like taste, is a sense of contact and everything like it is irrelevant for receiving information in a classroom.

Sense of sight - is a sense of distance, targeted, but with large aperture very important in receiving information and storing it in the waking state. This is also why, in the educational process has always appealed to sketches, drawings, icons, illustrations, photographs and then microfilm, slides, film and computer graphics utility products. Effective understanding of information transmitted in this way and discerns their authenticity cannot be complete however without a proper comment, verbal or written.

Sense of hearing - is a sense of distance, incoming from all directions both waking and sleeping. He gives an essential path for the transmission of information and their reception both the warning and those for information and communication. Through thinking this sense provides the fastest browse of the distance between "perception" and "understanding" [4]. The sense of hearing is the underlying appearance of language. The purpose of language is to help the knowledge and the transmission of knowledge. We appreciate that speech is superior in cognitive terms both of indication and of exhortation to "see" something. This is because language allows the "question" and the responses to it can be converted to other questions and such dialog appears and debate that is true two-way transmission of knowledge 


\section{Conclusions}

Research vs. Education. An overview over the results achieved by students in technical education in Romania over the last quarter century reveals that they have been continuously decreasing. Main causes could be:

- the management of higher education institutions remained in the hands of teachers, the formation mostly scholastic, for which research work is not a defining part of their work. Paradoxically, although master studies would be to prepare students for future doctoral research work, among the subjects studied there was not one which will reveal the mysteries of research.

- higher education institutions in Romania today, cannot develop creative skills. Attending examination, are found mainly, university professors do not appreciate the student who mostly "understand" but the student who, above all "know", when in fact, science needs people who, above all "understand".

- the selection of young researchers is left to the institutes of higher education, where only to the end of their studies, based on skills, but particularly on the marks obtained, most suitable graduates are selected for this type of activity and directed to doctoral studies. Only here they come into contact with scientific work and only now can they put out any creative possibilities - over 23 years, so with a delay of 4 or 5 years from when the experts say that talent is recognizable.

Harmonious development of the theory and practice proves to be imperative for any nature knowledge domain. Each generalization towards theory must necessarily be verified experimentally. The high level of research is a prerequisite for healthy development of any science. To get access to such a goal requires researchers, both fundamental and the experimental field, and in the same degree in engineering specialists are needed who understand the researcher's results and to highlight the practical applications.To these issues should be given importance, at least fair if not increased, and this because, in addition, lack of young scientists brings decreasing fast progress, both at the level of the teacher and at the level of experimented scientist or engineer from industry. Moreover, there are still people who believe that any scientific work must have a direct technique consequence. They are those who confuse research work with engineer work, fundamental research with productive engineering. This confusion should disappear completely and the selection of future research among future engineers should be continuous throughout the regular studies and after a unitary procedure which have the basic competency criteria rigorously defined.

\section{Classical vs. Modern in Education Techniques}

The tandem hearing-sight is essential in learning. We appreciate that for the knowledge transfer activities, speech is more important than sight. To assert that the Earth revolves around the Sun even "see" that it is the reverse to say that the universe is infinite when you "see" that everything around you is finished, it is a paradox that only verbal language made it possible. The lecture, dialogue, debate, book remain the main ways of counteracting the trend they have audio-visual media to weaken the critical spirit. Any excess is negative. The teacher's role is not to be transferred on behalf of courses "on-line", of electronic "books", or documentary films teaching, demo movies, either with verbal explanations or not, either subtitled or not. Graphics "transcribe" a talk of essence and less "describes" phenomena. "Such as, current audiovideos can lead to destruction of both human creativity and the reunification and its progress. Choose depends on the teacher how to use the technique. In addition, exacerbating the sense of sight at the expense of other senses is the greatest misfortune of alphabet writing, continued with icons and other graphic techniques electronics [2]. IT techniques are just an aid, not an alternative. Teaching in the traditional oral way is irreplaceable! A true teacher or scientist, teaches himself when explaining students. On the other hand, trying to explain issues clearly and concisely, he checks his own knowledge, reworded, students answer questions, clarify and classify, in a continuous creative manner. It thus creates the premise that students will be able to know better than their teacher education discipline - it is actually the true progress.

When not communicating with combative, contradictory or not the research areas is the "fashionable" way, is sure sign that the university feels hint of old age or sclerosis [1].

Direct teacher-student contact is crucial. Only when hear the man and eventually see his facial expressions and his workplace or laboratory, occurs confidence to his knowledge and work. For the same reasons, no book, IT files or movie, cannot replace the teacher! Regarding the presentation of the course, Rutherford said: "As little slide! Whenever the light goes out, some other listeners leaving the room ..." Hypertrophy use of IT in education to the detriment of oratory or reading, increases life of inner and outer damage multiplied spontaneous reflexes at the expense of the rational. To conclude, teaching techniques, both traditional and modern should not be mutually exclusive but complementary. Have tried a mix 
between classic and modern teaching methods, the teacher having preponderant role and IT techniques only providing support of the lecture.

\section{References}

- Prince, D., Little Science, Big Science, New York, (1963)

- Nitzsche, F., Stämtliche Werke, Kritische Studienausgabe in 15 Bäden, hg. von Giorgio Colli und Mazziano Montinari, mit einem Gesamtregister von Jorg salaquarda, Deutscher Taschenbuch Verlag, Walter de Gruyer, Munchen, (1980).

- Dgastra, R., Der witternde Prophet. Über die Feinsinnigkeit der Nase in das Schwinden der Sinne, hg. von Dietmar Kamper und Christof Wulf, Suhrkamp, Frankfurt a. M., (1984).

- Wald, H., Limbaj şi valoare, Editura Enciclopedică Română, Bucureşti,, (1973).

- Mc Luhan, M., Pour comprendre les media, Montreal, H.M.H., (1968).

- Kapita, P.L. Experiment, teorie, practică, Editura Politică, Bucureşti, (1981)

- Voicu, B., Studiul sociologic „Absolventii recenti de învătământ superior şi integrarea lor pe piata muncii”, Documents of Final Conference on Strategic Project POSDRU /2/1.2/S/2., București, 14.Nov. 2011, available at http://docis.acpart.ro/upload/noi/Prezentare_DOCIS.pdf, (2011). 